\title{
LOS 21 A TRAVÉS DE LA MIRADA DE ELADIO
}

Mariana Loaiza Giraldo*, Juan David Franco Becerra**,

Lina María Carvajal Araújo***

\section{Resumen}

El presente trabajo de investigación en curso, consiste en la recopilación de hechos históricos, anécdotas y vivencias de un grupo familiar conocido como Los veintiuno, pertenecientes a la vereda de Las Mangas, ubicada al sur de Santa Rosa de Cabal y aledaña a la ciudad de Pereira por la cuenca del río Otún. Los cuales han aportado de manera significativa a la formación de esta comunidad a través de valores y enseñanzas, elementos que son primordiales y que deberían prevalecer en el tiempo para dar cuenta de su trayectoria y ser fuente de recuerdos para ellos y generaciones venideras.

Esta investigación es la primera fase del proyecto en donde gracias a la recolección de historias, vivencias, fotografías y grabaciones de la familia se llegó a la contextualización de una idea, la cual será la base del proyecto y dará paso a la creación de un libro ilustrado.

Palabras clave: co-creación, familia fundadora, diseño social, memoria histórica, libro ilustrado.

* Estudiante, Diseño Gráfico. Fundación Universitaria del Área Andina. Correo: mloaiza21@estudiantes.areandina.edu.co

**Estudiante, Diseño Gráfico. Fundación Universitaria del Área Andina. Correo:jfranco30@ estudiantes.areandina.edu.co

*** Docente asesora, Fundación Universitaria del Área Andina. Correo: Icarvajal2@ areandina.edu.co 


\section{Introducción}

A partir de la información obtenida a través de las entrevistas realizadas a diferentes personas de esta comunidad, se puede afirmar que la manera en la que se han transmitido las tradiciones dentro de los núcleos familiares que la conforman ha sido de forma oral; por lo cual, toda su riqueza e importancia histórica ha ido desapareciendo a través del tiempo, puesto que no hay presencia de material escrito o gráfico que dé a conocer los hechos, anécdotas, acontecimientos e importancia de la memoria histórica de la vereda Las Mangas desde su fundación hasta la actualidad.

Eladio Jaime Vallejo Giraldo, el séptimo miembro de Los veintiuno, su líder y el representante público en la comunidad, junto con conocidos y amigos del mismo, fueron quienes brindaron información e historias sobre las vivencias y acontecimientos dentro del territorio en el que habitan, una vereda llamada Las Mangas, ubicada al sur de Santa Rosa de Cabal y aledaña a la ciudad de Pereira por la zona de la cuenca del río Otún.

Así pues, la metodología cualitativa desde la observación participante y análisis del discurso, son fundamentales para la recolección de datos y hechos que complementen la memoria histórica de Las Mangas. Gracias a la integración del señor Eladio Jaime Vallejo Giraldo, nos brindó información, grabaciones, material escrito y gráfico, que evidenciara el crecimiento de su familia dentro de la comunidad y de cómo a través del tiempo fueron partícipes de la conformación y crecimiento de un pueblo, a partir de la unión entre sus integrantes y demás familias como lo son los Ramírez y los Valencia, formando así lo que hoy conocemos como la vereda de Las Mangas.

Entonces, desde el punto de vista social, el diseño gráfico tiene la posibilidad de generar mensajes que contribuyan positivamente a la sociedad, transmitiendo la información de forma clara y concisa, de tal manera que deje huella en las personas. En este caso, evidencia y plasma gráficamente la memoria histórica de Los veintiuno, así aporta a la recuperación de elementos importantes tanto de la familia como en la comunidad.

Por esta razón y desde nuestra labor como diseñadores gráficos con conciencia social e integrantes del semillero TAMBO, buscamos destacar a partir de un libro ilustrado algunos sucesos, anécdotas, historias, recuerdos, fotografías y vivencias de esta familia, y su relación con el corregimiento, los cuales consideramos que son fundamentales para la conservación de la memoria histórica de la región.

\section{Adentrándonos con la comunidad}

Para el desarrollo del proyecto, inicialmente se realizó un proceso de selección a partir del análisis de distintas opciones de comunidades ubicadas en Risaralda. Por tanto, al ver el interés en la recolección de la memoria histórica y la consolidación de una identidad para la comunidad se seleccionó a la vereda Las Mangas (ubicada al sur de Santa Rosa de Cabal y aledaña a Pereira y Dosquebradas por la cuenca del río Otún y la vía principal hacia la Florida). 
Para tener un primer acercamiento con la comunidad e iniciar un proceso de exploración, se tuvo en cuenta a un personaje perteneciente a dicho territorio, el cual posee el mismo interés de conservación histórica que nosotros. Fue entonces en donde exploramos diferentes lugares esenciales de la vereda, y a partir de allí se crea la necesidad de interactuar directamente con las familias fundadoras, para así integrarnos y conocer los hechos que los han transformado en una sola familia.

Aquí es donde la metodología cualitativa desde la observación participante tiene un papel muy importante para la recolección de datos y hechos que complementen la memoria histórica de Las Mangas, mediante la integración y la familiarización con la comunidad de la vereda participando de sus actividades cotidianas por un determinado tiempo.

Las personas con las cuales interactuamos, resaltan por su importancia dentro de esta al pertenecer a las distintas familias fundadoras: los Ramírez, Valencia y Giraldo.

Dentro de ellas, la familia Giraldo resalta por su apodo "Los veintiuno", nombre que se les atribuye por la gran cantidad de hermanos, siendo 23 en total, y su contribución a la comunidad.

No es de desconocer lo difícil que resulta mantener en esta actualidad una familia bastante numerosa y a la vez unida, puesto que las distintas situaciones tanto económicas como sociales e intrafamiliares que ocurren cotidianamente afectan constantemente su desarrollo. Teniendo presente lo mencionado, esto nos genera un acercamiento profundo a los 21, y a partir de allí nos contactamos con el señor Eladio Jaime Vallejo Giraldo, miembro actual de la junta de acción comunal, uno de los principales creadores del acueducto comunitario el cual dirigió durante 21 años, y figura principal de la familia.

A partir de dicho personaje, se utilizó el recurso de historia de vida como herramienta de la investigación cualitativa, quien nos brindó todo su apoyo y colaboración a la hora de realizar este proyecto, nos cuenta entonces historias, relatos y anécdotas de Los veintiuno. En medio de la conversación percibimos su gran interés por los valores familiares y el respeto que ha construido a través de los años y su búsqueda por hacerlos prevalecer con las siguientes generaciones de su familia.

Nuestro objetivo de investigación se centra principalmente en cómo contribuir por medio del diseño gráfico a la recuperación de algunas memorias históricas de la familia de los 21 , teniendo en cuenta su importancia dentro de la construcción del territorio de Las Mangas.

\section{Resultados}

Después de un proceso de indagación y búsqueda de referentes teóricos que dieran fundamento y solidez al proceso 
de investigación-creación, es pertinente evidenciar desde la "tangibilidad de la historia, la colonización de Risaralda y de Santa Rosa de Cabal y el diseño gráfico para la gente", como se plantea seguidamente.

\section{La tangibilidad de la historia}

Es fundamental tener clara la importancia del pasado en el desarrollo del presente y su trascendencia en él. Castell (2015) afirma: "Sin pasado no es posible un presente y futuro próspero, capaz de transformar y contribuir al desarrollo cultural, social, económico y político" (pp. 74-76). Así pues, afirmamos que también es clave resaltar a quienes han formado la historia, haciendo énfasis no solo en los que formaron parte de ella, sino también hay que brindarle la importancia a aquellos que aún construyen $\mathrm{y}$ forman el legado comprometedor, digno de reconocimiento.

\section{Colonización de Risaralda y Santa Rosa de Cabal}

De acuerdo con lo mencionado por Botero y Mayorga (1986), a partir de la década de los cincuenta se encontraban tres grupos poblacionales dentro de Risaralda, con diferentes ubicaciones. Entre ellas una comunidad indígena, quienes estaban en los municipios de Guática, Quinchía, Mistrató y Pueblo Rico. El siguiente grupo, conformado por antioqueños, ocupó los municipios ubicados al occidente del río Cauca. Y, por último, el grupo formado por inmigrantes antioqueños procedentes del sur del viejo Antioquia y Salamina, se ubicaron en Santa Rosa, Pereira y Marsella.
Así pues, Fermín López luego de su travesía desde Salamina da inicio a la colonización antioqueña, empezando por Santa Rosa de Cabal. Surgiendo así distintos grupos raciales, como el grupo indígena, el de paisas del suroeste a quienes los denominaron "Los Putañeros", el grupo afrodescendiente proveniente de la zona de plantaciones de caña de azúcar del Valle del Cauca, ubicado principalmente en la Virginia, y por último, el grupo de paisas de Abejorral (Salamina), quienes ocuparon Santa Rosa de Cabal, Dosquebradas, Pereira y Marsella. Así, Botero y Mayorga (1986) citan el planteamiento de Cardona:

Este grupo es pacífico, hogareño, emprendedor y visionario. En realidad, este grupo y en estas tierras es el que ha dado pábulo a la leyenda del superhombre paisa. En épocas recientes ha tomado, casi absolutamente, el liderazgo departamental. Es un grupo blanco y equilibrado políticamente. (p. 121)

Para finalizar, Santa Rosa de Cabal se funda el 13 de octubre de 1844 y en la actualidad cuenta con las siguientes cinco comunas: La Hermosa, Sur, Centro Sur, Centro Norte y Norte. A su vez, lo componen cinco corregimientos: $\mathrm{El}$ Español, Santa Bárbara, El Manzanillo, Cedralito - Las Mangas y La Capilla.

\section{Diseño gráfico para la gente}

Jorge Frascara, en su libro Diseño gráfico para la gente, nos introduce la importancia de la labor dentro del ámbito social, que se debe realizar a la hora de construir mensajes visuales con el propósito de transmitir información que logre afectar al público en aspectos como 
el conocimiento, las actitudes y el comportamiento. Frascara (2000) menciona:

El diseñador es responsable por el desarrollo de una estrategia comunicacional, por la creación de los elementos visuales para implementarla y por contribuir a la identificación y a la creación de otras acciones de apoyo destinadas a alcanzar los objetivos propuestos, es decir, la creación de esa realidad deseada. (p. 5)

Así pues, podemos afirmar que la comunicación nace a partir del deseo de modificar una realidad existente en una realidad deseada.

\section{Un descubrimiento que nos impulsa}

Con la recolección de la información oral y escrita, en la que se obtuvieron grabaciones, anécdotas e historias que fueron primordiales para la construcción de la familia de Los veintiuno y los valores con los que se reconocen así mismos actualmente, se inició un proceso minucioso en donde comenzamos a separar y analizar cada uno de los elementos encontrados que fueran importantes para nuestra investigación.

Aquí mostramos fragmentos de un escrito realizado por el mismo don Eladio, en donde relata su autobiografía, la historia de su familia con los nombres de sus 20 hermanos y hermanas, junto al contexto de la fundación y desarrollo de la vereda de Las Mangas.
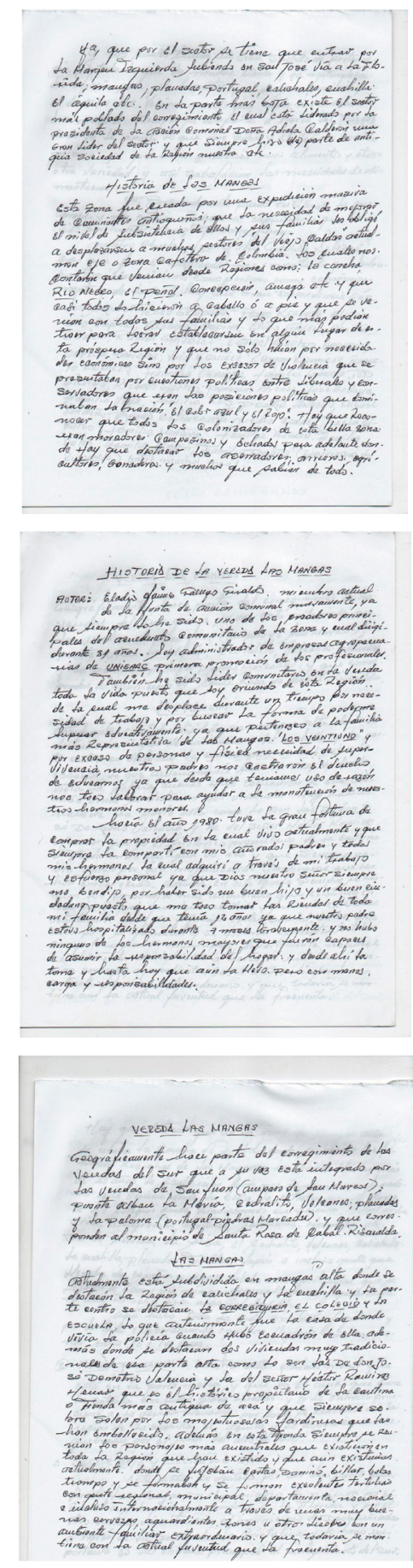

[Fotografía de Mariana Loaiza y Juan David Franco]. (Las Mangas, 2019). Documento escrito por Eladio Jaime Vallejo Giraldo: Historia de Las Mangas. 
Con la ayuda de los escritos del propio don Eladio, fue para nosotros primordial acercarnos más a su hogar y zonas aledañas, para así tener una idea más clara de su territorio y de esta manera obtener una evidencia visual que apoye la propuesta gráfica a desarrollar en este proyecto.
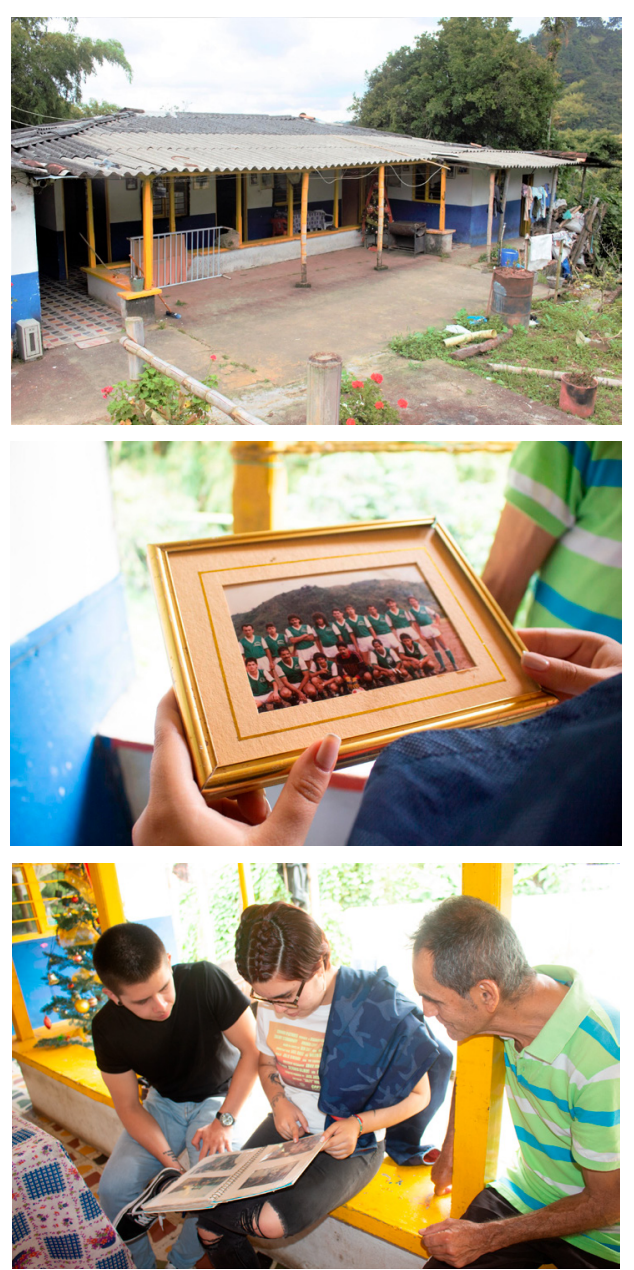

[Fotografía de Mariana Loaiza y Juan David Franco]. (Las Mangas, 2019). Archivos del Hogar de los 21 .

Nos encontramos entonces con una casa pequeña, bastante acogedora, en donde toda la familia ha tenido diferentes experiencias; en ella encontramos distintos elementos, como las flores, macetas grandes de piedra, portarretratos por toda la casa en donde se apreciaban los distintos integrantes de esta familia; y con ello varios álbumes fotográficos con el que nos enseñaba de manera clara y concisa las características de cada uno de sus hermanos, además de contarnos nuevas historias que lo marcaron y que se ven claramente representadas en el álbum.
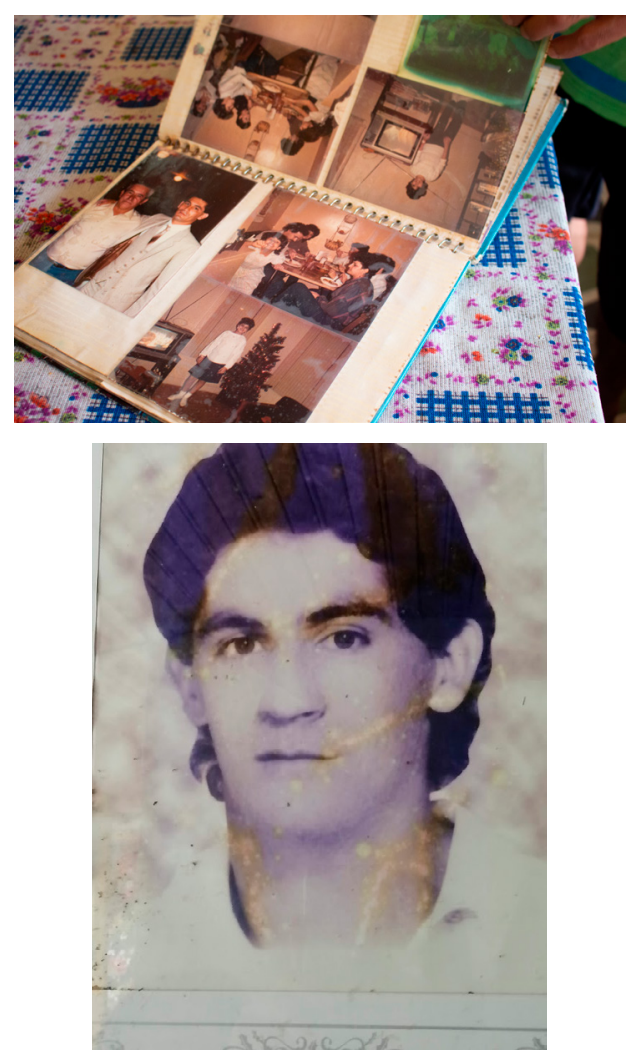

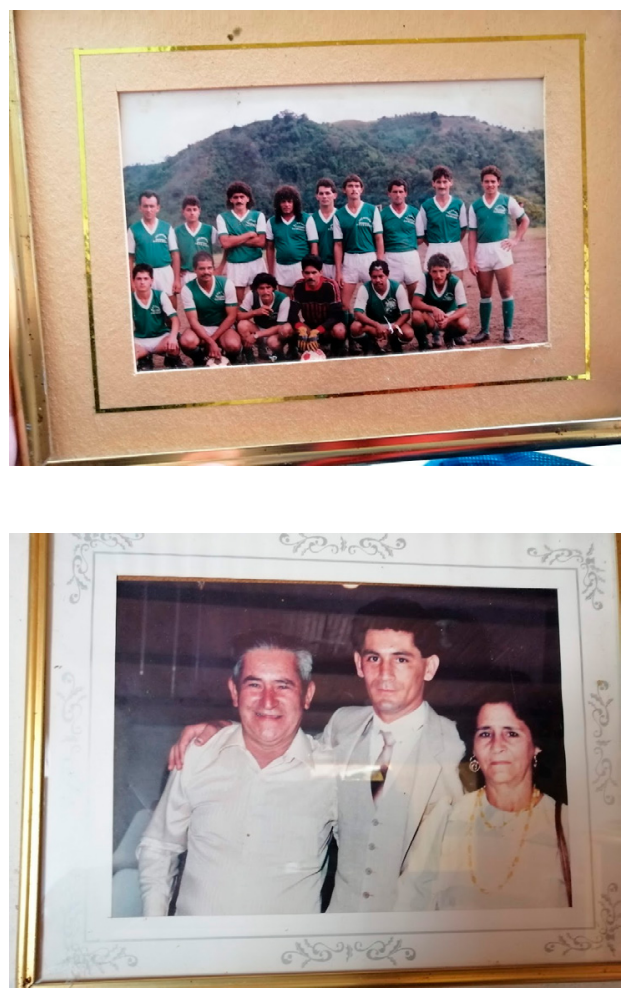

[Fotografía de Mariana Loaiza y Juan David Franco]. (Las Mangas, 2019). Archivos del Hogar de los 21.

Teniendo en cuenta lo anterior, se pretende entonces crear un producto gráfico que logre plasmar y resaltar de manera concreta las características de Los veintiuno, y a su vez elementos importantes del desarrollo de la comunidad dentro de la vereda de Las Mangas; generando así un impacto por medio de un libro ilustrado, el cual es una recolección de historias, sucesos, anécdotas, vivencias y recuerdos de la familia, realizados a partir de las palabras del señor Eladio Jaime Vallejo Giraldo, representante de Los veintiuno.

En este punto del desarrollo del proyecto, se dará paso a un trabajo de co-creación con la familia o comunidad, del cual se obtendrán elementos importan- tes, como la mirada que tienen de ellos mismos, para así crear ilustraciones que vayan acorde con su visión intrafamiliar. Y así se logrará obtener un producto final que sea tanto de ellos como de nosotros para generar un aporte e impacto positivo a la comunidad de Las Mangas y a la familia de Los veintiuno.

\section{Discusiones}

Al realizar la investigación en la vereda de Las Mangas, se llegó a la conclusión de que no hay existencia de material escrito y gráfico que refleje los hechos históricos de la conformación de las familias, y de dicho territorio. Sin embargo, y a partir del diálogo con distintas personas como amigos, familiares y conocidos en la vereda, se logra resaltar que la familia Gallego Giraldo o también llamados Los veintiuno son de gran importancia dentro de la historia de la formación de Las Mangas.

Por otra parte, la labor de los diseñadores gráficos ha tomado más fuerza por su preparación a la hora de investigar exhaustivamente para llegar a una solución clara, logrando así representar valores y elementos emocionales que transmiten de manera correcta el mensaje propuesto. El libro, por su parte, brinda riqueza cultural a la sociedad y encamina al espectador a considerar sus propios valores y plantearse un nuevo punto de vista; es aquí en donde tomamos como referencia la familia Gallego Giraldo por la unión y respeto entre ellos, y los demás integrantes de la comunidad, valores que, a su vez, pretenden ser transmitidos a las nuevas generaciones.

Considerando que la existencia de material fotográfico de la familia y su hogar 
es fundamental para el entendimiento del contexto en el que se encuentran, se determina plasmar tales características de manera gráfica para su transmisión dentro de la comunidad y las siguientes generaciones, y así no perder las tradiciones e historias que formaron a tan bondadosa familia. Como lo plantea Armando Silva en su libro Álbum de familia: "Sus imágenes viven para ser escuchadas entre generaciones" (2012, p. 72).

\section{Referencias}

1. Botero, C., \& Mayorga, O. (1986). Poblamiento y colonización de Risaralda. Revista Páginas, 14, 121.

2. Castell-Florit, S. P. (2016). La tangibilidad de la historia. Cuba: INFODIR, 22, 74-76.

3. Frascara, J. (2000). Diseño gráfico para la gente. Buenos Aires.

4. Hernández, R. (2014). Metodología de la investigación. México.

5. Le Compte, M. (1995). Un matrimonio conveniente: diseño de investigación cualitativa y estándares para la evaluación de programas. Revista Electrónica de Investigación y Evaluación Educativa, 1(1).

6. Moreno, C. (2014). Apuntes sobre diseño gráfico: teoría, enseñanza e investigación. Bruselas.

7. Nora, P. (1997). Les lieux de mémoire. París.

8. Silva, A. (2012). Álbum de familia. Medellín: Universidad de Medellín. 